Cahiers $d u$ MONDE RUSSE

\section{Cahiers du monde russe}

Russie - Empire russe - Union soviétique et États indépendants

$51 / 4 \mid 2010$

Sciences humaines et sociales en Russie à l'Âge d'argent

\title{
Marlène Laruelle, Le Nouveau Nationalisme russe
}

\section{Cécile Vaissié}

\section{(2) OpenEdition}

1 Journals

\section{Édition électronique}

URL : https://journals.openedition.org/monderusse/7426

DOI : 10.4000/monderusse. 7426

ISSN : $1777-5388$

Éditeur

Éditions de l'EHESS

\section{Édition imprimée}

Date de publication : 25 novembre 2010

Pagination : 782-784

ISBN : 978-2-7132-2316-7

ISSN : $1252-6576$

Référence électronique

Cécile Vaissié, "Marlène Laruelle, Le Nouveau Nationalisme russe », Cahiers du monde russe [En ligne], 51/4 | 2010, mis en ligne le 09 décembre 2011, consulté le 02 septembre 2022. URL : http:// journals.openedition.org/monderusse/7426; DOI : https://doi.org/10.4000/monderusse.7426

Ce document a été généré automatiquement le 2 septembre 2022

Tous droits réservés 


\title{
Marlène Laruelle, Le Nouveau Nationalisme russe
}

\author{
Cécile Vaissié
}

\section{RÉFÉRENCE}

Marlène LARUELLE, Le Nouveau Nationalisme russe. Des repères pour comprendre.

Paris : L'œuvre Éditions, 2010, 374 p.

1 Alors que l'une des questions à l'agrégation de russe 2011 et 2012 porte sur « patriotisme et nationalisme, d'Alexandre III à Poutine ", le nouveau livre de Marlène Laruelle propose - c'est son sous-titre - « des repères pour comprendre » l'évolution de ces deux courants, depuis la chute de l'URSS jusqu'à aujourd'hui. L'historienne estime que la « frénésie nationaliste » russe a paradoxalement pour source la quête d'une certaine normalité : il s'agit d'assurer la cohésion sociale et de légitimer les élites, ce qui, d'après cet ouvrage, ne pourrait se faire qu'en réhabilitant le patriotisme. Ce dernier point est contestable, mais l'auteur a raison de souligner qu'en Russie, le nationalisme n'est pas propre à la seule extrême droite, qu'il s'étend à l'ensemble du pays et est même « la langue politique majeure $[. .$.$] au sens où tous les partis la pratiquent ».$

2 Marlène Laruelle constate d'abord que les changements qui se sont multipliés depuis la perestroïka ont entraîné une forte montée de la xénophobie, devenue massive dans une population largement dépolitisée. Si, au début des années 1990, cette xénophobie est liée à la paupérisation de certains groupes sociaux, ce n'est plus le cas dès la seconde moitié de cette même décennie. Les études du Centre Levada montrent en effet que la xénophobie augmente alors dans toutes les couches de la société, et plus rapidement encore dans celles qui y étaient jusque-là peu sensibles : les habitants des grandes villes, ayant une éducation supérieure et des activités culturelles régulières. Depuis le début des années 2000, les milieux sociaux les plus aisés et les plus cultivés sont statistiquement aussi xénophobes que les moins favorisés. En outre, les jeunes sont plus xénophobes que leurs aînés et se positionnent davantage en faveur du slogan « la Russie aux Russes 
[ethniques]». Or, c'est dans ce contexte que se développe le «nouveau nationalisme russe ».

$3 \quad$ L'historienne dresse un panorama des mouvements se revendiquant de cette tendance et les scinde en trois, en fonction de leur rapport au pouvoir central et non des idées qu'ils prônent. Le « camp extraparlementaire » - celui des mouvements qui ne siègent pas à la Douma et où le nationalisme représente une opposition - inclut, juste après la chute de l'URSS, de nombreux groupes, influencés, selon les cas, par le fascisme italien, le nazisme allemand, le bolchevisme ou le monarchisme. Un seul d'entre eux n'est pas moribond à la fin des années 1990 : le parti national-bolchevik, créé par l'écrivain Èduard Limonov, le théoricien néo-eurasiste Aleksandr Dugin et le chanteur rock Egor Letov. Le mouvement skinhead devient très visible à partir du début des années 2000, il affiche des positions, pour l'essentiel, néonazies et bénéficie du soutien plus ou moins discret de la classe politique et des institutions judiciaires. Ces dernières années, le parti national-bolchevik, interdit et combattu, s'est rapproché des libéraux anti-Putin, alors que les autres groupes extraparlementaires se sont recentrés autour du refus d'une immigration massive. Dès lors, ce nationalisme - qui craint les migrants, le "péril jaune» et la «menace islamiste " - développe l'idée que la Russie appartient à un "monde blanc", comme l'Europe et les États-Unis, même s'il continue de promouvoir le ressentiment envers l'Occident.

deuxième courant est celui des "partis protestataires", qui se disent dans l'opposition mais siègent à la Douma : le PC, le LDPR (Parti libéral-démocrate de Russie) et Rodina - ou ce qu'il en reste après la naissance de Russie juste. Ces partis développent un nationalisme populiste : ils critiquent les élites, ont un projet politique autoritaire mais non totalitaire, conservateur et non révolutionnaire, et ils appellent à la primauté du peuple russe sur les étrangers.

5 Enfin, le parti dirigeant Russie unie transforme le nationalisme en un "centrisme conservateur»: pour comprendre cette évolution, Marlène Laruelle analyse la renaissance du patriotisme sous les auspices du Kremlin au cours des deux dernières décennies. Dès la seconde moitié des années 1990, certains hommes politiques articulent l'expression publique du sentiment national autour du thème fondateur de la puissance. Puis Putin insiste sur la notion de fierté, qui conditionnerait le redressement de la Russie et, encore en tant que Premier ministre, expose les trois "valeurs» qu'il juge fondamentales: le patriotisme, la puissance (deržavnost') et le sens de l'État (gosudarstvenničestvo). Par la suite, il défend classiquement la conception d'un " patriotisme " positif et constructif, par opposition à un " nationalisme » négatif et extrémiste. Russie unie développe alors un discours conservateur et refuse toute idéologisation trop poussée, ce qui lui permet de s'affirmer comme un «parti pluripartite».

L'historienne déduit de cette segmentation que le nationalisme établit, dans une société russe très divisée, un double consensus: entre l'ensemble des citoyens, et entre ces derniers et les élites politiques. Le thème de la patrie permettrait d'atténuer les clivages politiques, de nier les divisions sociales et d'effacer la multiplicité des références culturelles. C'est pourquoi, au cours des dix dernières années au moins, le Kremlin a repris ce terme aux mouvements extraparlementaires ainsi qu'aux partis d'opposition, et a élaboré un programme patriotique. Celui-ci se concentre sur plusieurs éléments que Marlène Laruelle décrit: juxtaposition des symboles tsaristes et soviétiques; institutionnalisation d'une mémoire historique officielle qui implique de repenser les 
fêtes nationales; instrumentalisation de l'orthodoxie, même si la capacité de l'Église orthodoxe à agir sur l'État semble relativement réduite; enfin développement d'un patriotisme militarisé. L'auteur évoque l'hypothèse, confirmée par de nombreux indices, que la thématique patriotique soit avant tout impulsée et soutenue par des cercles liés aux services secrets, puis survole les manifestations de ce patriotisme dans la culture.

Un curieux sentiment se dégage de ce panorama très riche: les idées, présentées en détail, n'auraient, au bout du compte, pas grande importance, un point de vue repris et développé dans la belle thèse récemment soutenue par Véra Nikolski sur deux mouvements actuels, le Parti national-bolchevik (NBP) et l'Union de la jeunesse eurasiste (ESM) ${ }^{1}$. Marlène Laruelle note ainsi que les skinheads ne sont pas à la recherche d'un message politisé mais « d'un encadrement affectif rendu possible par l'appartenance de groupe et le refus de la société des adultes ». Elle souligne le « flou doctrinal » de Rodina et relève que Vladimir Putin est «connu pour préférer les méthodes de management aux principes idéologiques». Du coup, la rhétorique patriotique développée depuis son premier mandat reste vague et imprécise dans sa définition même de la Russie, tandis que les paradoxes se multiplient. Russie unie, dont les discours sont à la fois libéraux et étatistes, prône ainsi une Russie européenne mais non occidentale et en opposition à l'Union européenne. L'orthodoxie est associée au patriotisme poutinien, mais de très nombreux Russes se disent à la fois orthodoxes et non croyants, peu d'entre eux étant de fait pratiquants.

Sans doute peut-on regretter que, dans cet ouvrage, les concepts de patriotisme et de nationalisme ne soient pas définis avec assez de précision. Marlène Laruelle note la connotation négative que Vladimir Putin donne au second terme, mais elle-même l'emploie de façon neutre. Elle souligne la réappropriation du concept de " patriotisme " par le pouvoir mais n'explore pas la polysémie de ce terme qui ne désigne pas la même chose pour tous les locuteurs. En outre, elle aurait sans doute pu approfondir davantage l'analyse des phénomènes constatés et de leurs causes : quel est le rôle des intellectuels dans la construction des différentes formes de nationalisme? Pourquoi la société russe adhère-t-elle, ou non, à tel discours ou telle mesure?

Dans sa conclusion, l'historienne avance des idées très pertinentes qui vont à l'encontre de certaines représentations usuelles. Elle souligne ainsi que le patriotisme russe actuel est, avant tout, une " posture ", une " étiquette " pour affirmer l'unité retrouvée entre peuple et dirigeants. Le véritable clivage qui structure la scène politique serait le ralliement, ou non, à l'appareil présidentiel, mais il est passé sous silence au nom d'une division binaire opposant patriotes aux non patriotes. Ou, en d'autres termes, «les nôtres » aux " autres ». Les nuances idéologiques sont donc bien secondaires : comme le déclare Marlène Laruelle, le patriotisme russe est « un contenant sans contenu, appelant à un consensus mou ". Néanmoins, à ses yeux, il s'accompagne d'une volonté que le Kremlin aurait de s'ancrer dans l'Europe - volonté qui parait pourtant bien fluctuante et serait une « forme d'occidentalisation de la Russie ». Une idée intrigante et, là encore, paradoxale. 


\section{NOTES}

1. Véra Nikolski, «Le moment escapiste. Militantisme et production théorique dans une conjoncture de crise. Deux mouvements de jeunesse radicaux (NBP et ESM) dans la Russie contemporaine ", thèse en science politique sous la direction de Frédérique Matonti, université de Paris 1 Panthéon Sorbonne, 2010. 